\section{SHORT-COURSE IMMUNOSUPPRESSION AFTER TRACHEAL ALLOTRANSPLANTATION IN DOGS}

It is desirable to minimize immunosuppression after allotransplantation. We examined the usefulness of a short course of immunosuppression after tracheal allotransplantation in 35 dogs. Five animals with six-ring tracheal autografts served as controls (group $I, n=5$ ). Thirty animals with six-ring tracheal allografts were randomly classified into five groups as follows: no immunosuppression (group II, $n=6$ ), azathioprine for only 1 postoperative week (group III, $n=7$ ), azathioprine for 2 postoperative weeks (group IV, $n=7$ ), azathioprine for 3 postoperative weeks (group $\mathrm{V}, \boldsymbol{n}=5$ ), and mizoribine for 3 postoperative weeks (group VI, $\boldsymbol{n}=\mathbf{5}$ ). All allografts in groups II through VI sustained rejection, but there was no difference in mononuclear cell infiltration of the grafts among the groups. The only grafts with long-term viability were those in groups I and VI, as demonstrated by graft patency and epithelialization. We conclude that immunosuppression with mizoribine for only a short course after transplantation may allow long-term viability of tracheal allografts. (J Thorac CARDIOvasC SuRg 1995;109:910-7)

Ryoichi Nakanishi, MD, Kosei Yasumoto, MD, Kitakyushu, Japan, and Takayuki Shirakusa, MD, Fukuoka, Japan mmunosuppressive agents are necessary to prevent rejection of transplanted organs. However, long-term administration of these agents is associated with significant complications including the development of malignant disease. ${ }^{1}$ Therefore, minimizing immunosuppression after transplantation is desirable.

Tracheal allotransplantation generally requires immunosuppression. ${ }^{2}$ However, it has been reported that tracheal allotransplants, in contrast to other organ transplants, induce only weak graft rejection even in the presence of major histoincompatibility. $^{3}$ If this is the case, minimal immunosuppression may prevent rejection. To date, no report on the required strength of immunosuppression for tracheal allografts has been presented.

This study was undertaken to assess the effective-

From The Second Department of Surgery, School of Medicine, University of Occupational and Environmental Health, 1-1 Iseigaoka, Yahatanishi-ku, Kitakyushu 807, Japan, and The Second Department of Surgery, School of Medicine, Fukuoka University, 45-1, 7-chome Nanakuma, Jonan-ku, Fukuoka 814-01, Japan.

Received for publication May 26, 1994.

Accepted for publication Oct. 26, 1994.

Address for reprints: Ryoichi Nakanishi, MD, The Second Department of Surgery, School of Medicine, University of Occupational and Environmental Health, 1-1 Iseigaoka, Yahatanishi-ku, Kitakyushu 807, Japan

Copyright @ 1995 by Mosby-Year Book, Inc.

$0022-5223 / 95 \$ 3.00+0 \quad \mathbf{1 2 / 1 / 6 1 4 9 5}$ ness of a short course of immunosuppression after tracheal allotransplantation because irreversible early rejection reactions may occur after transplantation without immunosuppression. In cases with weak rejection reactions, a short course of postoperative immunosuppression maintains long-term allograft viability, even if the late rejection occurs. A short course of immunosuppression is preferable to consecutive courses of immunosuppression in terms of side-effects.

\section{Materials and methods}

Animals. Thirty-five adult mongrel dogs weighing from 8.5 to $16.5 \mathrm{~kg}$ were premedicated with an intramuscular injection of ketamine hydrochloride $(20 \mathrm{mg} / \mathrm{kg})$. Five individual dogs and 15 pairs of dogs were placed in the supine position and anesthetized with an intravenous injection of pentobarbital sodium $(10 \mathrm{mg} / \mathrm{kg})$ and pancuronium bromide $(0.1 \mathrm{mg} / \mathrm{kg})$. Then they were intubated orally and connected to a pressure-limiting respirator. All animals received humane care in compliance with the "Principles of Laboratory Animal Care" formulated by the National Society for Medical Research and the "Guide for the Care and Use of Laboratory Animals" prepared by the National Academy of Sciences and published by the National Institutes of Health (NIH Publication No. 86-23, revised 1985).

Surgical technique. After an upper midline laparotomy, an omental pedicle, which was fed by the right gastroepiploic artery, was formed without a splenectomy. ${ }^{4}$ The trachea was then exposed after a midline cervical incision and was mobilized circumferentially. The fifth tracheal ring was the uppermost ring resected. A spiral endotracheal tube was positioned into the lower trachea 
after the resection of six tracheal rings. The resected trachea was used as an autograft in group I and switched between paired animals as an allograft in groups II to VI. The upper anastomosis was first completed with running 3-0 Dexon sutures (Davis \& Geck, Inc., Manati, Puerto Rico). Next, the membranous portion of the lower anastomosis was similarly sutured. The spiral endotracheal tube was then removed from the operative field and the oral endotracheal tube was passed through both the upper and lower suture lines. The lower anastomosis was subsequently completed. An omental pedicle was brought up via a diaphragmatic defect through the mediastinum to the cervical area. This pedicle was used to wrap each end of the graft. The cervical and abdominal incisions were then closed in the usual fashion.

Postoperative management. The animals received antibiotics for the first 14 postoperative days. The 30 animals in groups II to VI were randomly classified into five groups according to immunosuppression (Table I): group II $(n=6)$, no immunosuppression; group III $(n=7)$, azathioprine (Azanin; Tanabe Pharmaceutical Co., Ltd.: 5 $\mathrm{mg} / \mathrm{kg}$ per day) for 1 postoperative week; group IV $(n=$ 7), azathioprine for 2 postoperative weeks; group V ( $n=$ 5), azathioprine for 3 postoperative weeks; and group VI $(n=5)$; mizoribine (Bredinin; Asahikasei Co., Ltd.: 5 $\mathrm{mg} / \mathrm{kg}$ per day) for 3 postoperative weeks. All drugs were administered by mouth. Bronchoscopic examinations were performed weekly after the operation until these animals died of natural causes or were killed.

\section{Assessment of grafts}

Patency. The patency of the tracheal graft was assessed by calculating the percent patency after the animal had died. The graft percent patency was expressed as a proportion of the cross-sectional area (CSA) of the most stenotic site in the graft to the third tracheal ring below the cricoid cartilage in the recipient trachea. The CSA was calculated from the following formula: $\mathrm{CSA}=\mathrm{a} / 2 \times \mathrm{b} / 2 \times$ $\pi$, where a was the transverse diameter and $b$ was the sagittal diameter. ${ }^{5}$

Histologic assessment. All tissues were fixed in $10 \%$ formalin. Microscopic slides were made from longitudinal sections of the trachea and adherent omentum and stained routinely with hematoxylin-eosin. Thereafter, all specimens were examined with a light microscope. We attempted to quantify the viability of the orthotopic grafted trachea by subjectively evaluating the epithelial histologic characteristics. Infiltration by mononuclear cells was also assessed because this is closely associated with allograft rejection. ${ }^{6}$

EPITHELIAL REGENERATION. Epithelial regeneration was evaluated according to the following grading system: 0 , no epithelium; 1 , single-layer nonciliated epithelium; 2 , multilayer nonciliated epithelium; and 3, normal mucociliary epithelium. ${ }^{2}$ The epithelium of the grafts was assessed as a ratio of the epithelial regeneration score on a microscopic slide.

MONONUCLEAR CELL INFILTRATION. The severity of mononuclear cell infiltration was graded semiquantitatively from 0 to 3 , with 0 indicating absence of any abnormality, 1 mild (infiltration area $<30 \%$ of a microscopically visual field), 2 moderate $(30 \%<$ infiltration area $<70 \%)$, and 3 severe changes (infiltration area $>70 \%)^{7}$
Table I. Study groups

\begin{tabular}{ccccc}
\hline & & & \multicolumn{2}{c}{$\begin{array}{c}\text { Medication interval of } \\
\text { immunosuppressive agent }\end{array}$} \\
\cline { 3 - 5 } Group & $n$ & Grafting & Azathioprine & Mizoribine \\
\hline I & 5 & Auto & - & - \\
II & 6 & Allo & - & - \\
III & 7 & Allo & 7 & - \\
IV & 7 & Allo & 14 & - \\
V & 5 & Allo & 21 & - \\
VI & 5 & Allo & - & 21 \\
\hline
\end{tabular}

-, no medication. Azathioprine (Azanin, $5 \mathrm{mg} / \mathrm{kg}$ per day) and mizoribine (Bredinin, $5 \mathrm{mg} / \mathrm{kg}$ per day) were administered by mouth.

Statistical methods. The probability of survival was calculated by the Kaplan-Meier method. ${ }^{8}$ The significance of the differences in survival rate was computed by the log-rank test. ${ }^{9}$ All data as to patency, epithelial regeneration score, and mononuclear cell infiltration score of the grafts were presented as the mean and standard error. Statistical analysis was performed by means of the SAS software package (SAS Institute, Cary, N.C.). A $p$ value less than 0.05 was considered statistically significant.

\section{Results}

Bronchoscopic findings. All the tracheal allografts, except for those in group II, showed gradual relief of severe inflammatory changes during immunosuppression. After immunosuppression was discontinued, the allografts appeared similar to those without immunosuppression (group II). They showed progressive stenosis caused by granulation tissue or exposure of the cartilaginous rings, or both. The allografts of long-term survivors in groups IV and $V(\operatorname{dogs} 20,24$, and 25$)$ revealed that the stenosis was less severe. Autografts in group I and allografts in group VI demonstrated good patency and intact mucosa after the first postoperative month.

Survival (Table II). All animals in group I survived more than 1 month and were then killed for the purpose of assessing graft viability. Although it was hoped that all animals in groups II to VI would survive for a long period, almost all animals except for those in group VI died within 1 year. All animals in group VI were put to death 2 years after transplantation for the purpose of making apparent the difference between their survival and that of the animals in groups II to V. Thirteen (43.3\%) animals in groups II to VI died of airway stenosis from graft rejection. The mean survival time of each group was as follows: group II, 8 days; group III, 16 days; group IV, 30 days; group V, 36 days; and group VI, 797 days. In groups II, III, and IV one animal survived longer than 1 month. In contrast, all animals in 
Table II. Survival and allograft status

\begin{tabular}{|c|c|c|c|c|}
\hline Groups & $\begin{array}{c}\text { Dog } \\
(N o .)\end{array}$ & $\begin{array}{c}\text { Survival } \\
\text { (days) }\end{array}$ & Cause of death & Graft status \\
\hline \multicolumn{5}{|c|}{ No immunosuppression group } \\
\hline \multirow[t]{6}{*}{ Group II $(n=6)$} & 1 & 4 & General marasmus & Ischemic \\
\hline & 2 & 6 & Diaphragmatic hernia & Partial dissolution \\
\hline & 3 & 8 & Airway stenosis & Total dissolution \\
\hline & 4 & 12 & General marasmus & Partial dissolution \\
\hline & 5 & 18 & Airway stenosis & Partial dissolution \\
\hline & 6 & 38 & Airway stenosis & Midportion stenosis; large granulation \\
\hline \multicolumn{5}{|c|}{ Immunosuppression groups } \\
\hline \multirow[t]{7}{*}{ Group III $(n=7)$} & 7 & 8 & General marasmus & Ischemic \\
\hline & 8 & 9 & Diaphragmatic hernia & Ischemic \\
\hline & 9 & 14 & Airway stenosis & Total dissolution \\
\hline & 10 & 16 & Airway stenosis & Midportion stenosis; large granulation \\
\hline & 11 & 18 & Airway stenosis & Total dissolution \\
\hline & 12 & 22 & Tracheoesophageal fistula & Partial dissolution \\
\hline & 13 & 33 & Airway stenosis & Midportion stenosis; large granulation \\
\hline \multirow[t]{7}{*}{ Group IV $(n=7)$} & 14 & 21 & Airway stenosis & Midportion stenosis; large granulation \\
\hline & 15 & 25 & Airway stenosis & Overall stenosis; large granulation \\
\hline & 16 & 28 & Pneumonia & Almost healed; normal mucosa \\
\hline & 17 & 30 & General marasmus & Midportion stenosis; some granulation \\
\hline & 18 & 30 & Airway stenosis & Total dissolution \\
\hline & 19 & 31 & Airway stenosis & Malacia of the midportion, some granulation \\
\hline & 20 & 343 & Upper GI tract bleeding & Midportion stenosis; some granulation \\
\hline \multirow[t]{5}{*}{ Group V $(n=5)$} & 21 & 34 & Airway stenosis & Overall stenosis; large granulation \\
\hline & 22 & 34 & Pneumonia & Slightly healed; loss of mucosa \\
\hline & 23 & 36 & Airway stenosis & Midportion stenosis; large granulation \\
\hline & 24 & 93 & Diaphragmatic hernia & Almost healed; normal mucosa \\
\hline & 25 & 280 & Killed & Well healed; normal mucosa \\
\hline \multirow[t]{5}{*}{ Group VI $(n=5)$} & 26 & 771 & Killed & Almost healed; normal mucosa \\
\hline & 27 & 781 & Killed & Almost healed; normal mucosa \\
\hline & 28 & 797 & Killed & Slight stenosis; normal mucosa \\
\hline & 29 & 798 & Killed & Almost healed; normal mucosa \\
\hline & 30 & 811 & Killed & Well healed; normal mucosa \\
\hline
\end{tabular}

GI, Gastrointestinal.

groups V and VI survived more than 1 month. The cumulative survival was significantly longer in group VI than in groups II to V. Likewise, the survival in group $\mathrm{V}$ was significantly longer than in group II or III. There was no difference in survival among the groups (Fig. 1).

Graft status and percent patency (Table II). All the autografts in group I had normal appearing mucosa and good patency, and almost all were healed. Stenosis and dissolution of the allograft in groups II to VI were seen in 19 animals (63.3\%). No animal in group VI had significant stenosis (less than $60 \%$ of normal) or dissolution. In group $\mathrm{V}$, stenosis of the graft was seen in two of five animals. Allografts in the remaining three animals showed healing status. In groups II, III, and IV, more than $70 \%$ of animals had stenosis or dissolution (or both) of the allograft. Dissolution of the graft was seen in four of six animals in group II. The average graft patency was significantly better in group I than in groups II, III, IV, and V but did not differ from that of group VI (Fig. 2). The rates of stenosis or dissolution of the allograft decreased in proportion to duration of immunosuppression.

\section{Histology}

Epithelial regeneration. All the animals in group I had good epithelial regeneration in the autografts. Two animals (33\%) in group II, four (57\%) in group III, and five (71\%) in group IV demonstrated some reepithelialization of the allografts. These allografts had partial restoration of the epithelium, which was almost completely occupied with a single layer of nonciliated epithelium (Fig. 3). In groups V and VI, all allografts demonstrated epithelial regeneration. Single-layer and multilayer nonciliated epithelium was often seen in the allografts of group V. Allografts in group VI often demonstrated normal mucociliary epithelium (Fig. 4). The average epithe- 

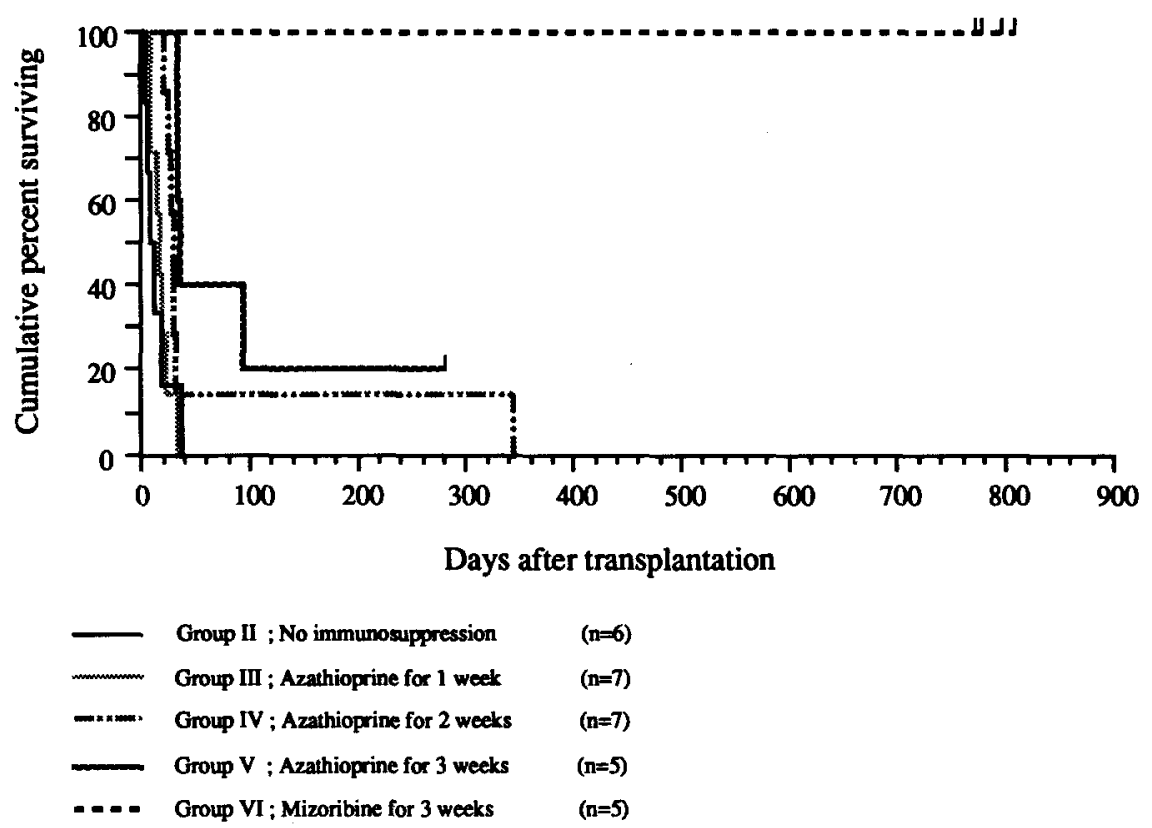
$(n=6)$
$(\mathrm{n}=7)$
$(n=7)$
$(n=5)$
$(n=5)$

Fig. 1. Cumulative percent survival after tracheal allotransplantation in groups II to VI. The survival of group VI differed significantly from the survival of other groups (groups VI versus II, $p=0.0065$; VI versus III, $p=0.0057$; VI versus IV, $p=0.007$; and VI versus $\mathrm{V}, p=0.0094$ ). Survival in group V differed significantly from the survival of groups II $(p=0.0486)$ and III $(p=0.0057)$. In other comparisons of survival between groups, there was no difference.

lial regeneration score of grafts in group I was significantly better than that of groups II, III, IV, and V but did not differ from that of group VI (Fig. 5).

Mononuclear cell infiltration. All allografts except for those in group VI revealed a slight to moderate mononuclear cell infiltration. Allografts in group VI demonstrated only slight infiltration by mononuclear cells. However, there was no significant difference in the mononuclear cell infiltration score among groups II to VI (Fig. 6).

The perichondrium of the cartilaginous rings and the cartilage itself was destroyed by mononuclear cells in some of the allografts in all groups except for group VI. The cartilage of the allografts in group VI retained their structural integrity. Interstitial damage was moderate to severe in groups II to IV but was only mild in group VI. The grafts in group V had intermediate interstitial damage between groups II to IV and VI. Proliferation of granulation tissue and hemorrhage was seen in almost all the allografts in groups II to IV but was rarely seen in group VI. Necrosis of the allografts was seen in animals who survived less than 30 days in groups II to $\mathrm{V}$ but was not seen at all in group VI. Moderate

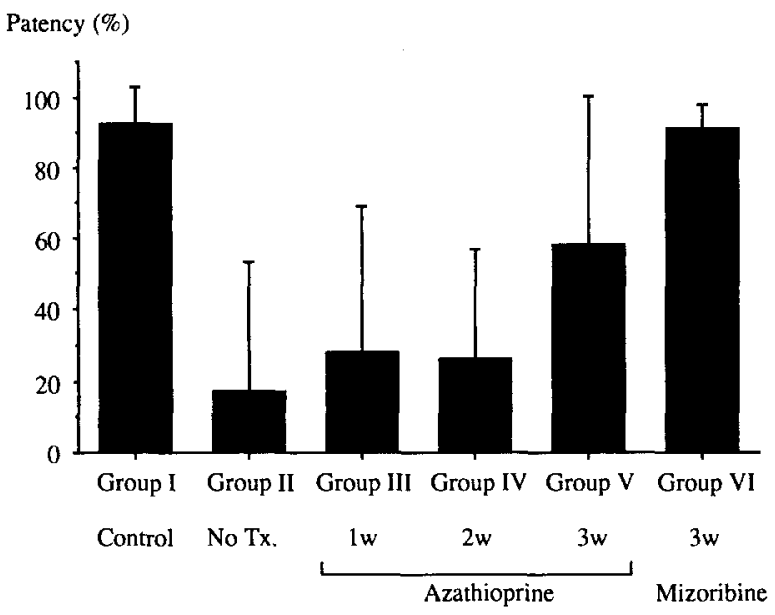

Fig. 2. Average graft patency. Data are presented as mean \pm standard error. No $T x$. indicates no treatment. The average patency of group I differed significantly from the patency of other four groups (groups I versus II, $p=$ 0.0123 ; I versus III, $p=0.0316$; I versus $\mathrm{IV}, p=0.0149$; and I versus $\mathrm{V}, p=0.0381$ ), but did not differ significantly from the patency of group VI $(p=0.4443)$. The average patency of group VI differed significantly from the patency of groups II, III, and IV. 


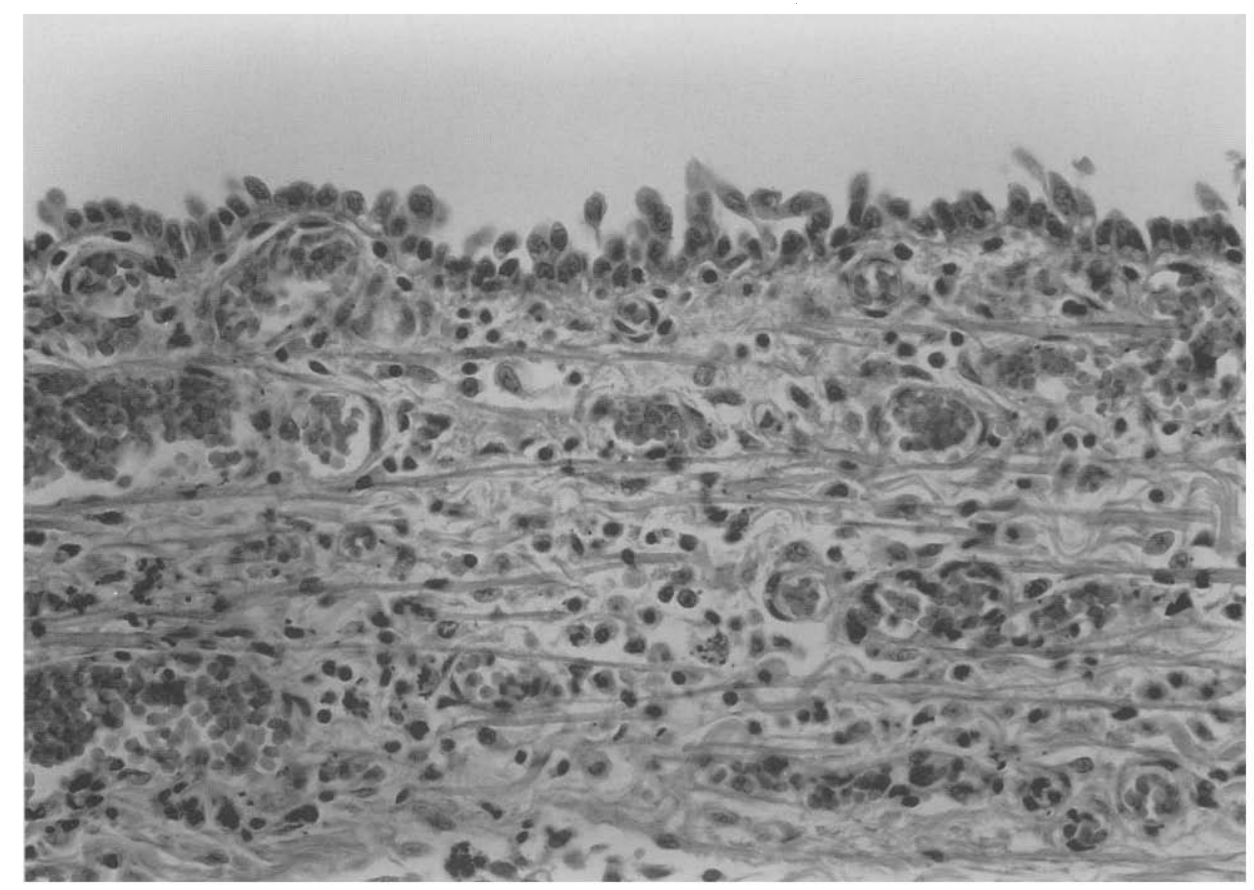

Fig. 3. Histologic study of an allograft of canine trachea on the postoperative day 343 in group IV (dog 20 ). The epithelium is partially restored (32.5\%) and is composed of a single layer of nonciliated epithelium alone (epithelial regeneration score $=0.325$ ). The mononuclear cells infiltrate moderately into the subepithelial region of the allograft. (Hematoxylin and eosin; original magnification $\times 400$.)

to severe inflammation occurred in all of the remaining allografts of groups II to IV. In contrast, allografts in group VI showed only slight inflammatory changes.

\section{Discussion}

With few exceptions, tracheal allotransplantation has been largely unsuccessful. Two major difficulties have been encountered. ${ }^{10}$ One is the revascularization of the devascularized tracheal graft. The other difficulty is rejection. Problems with revascularization have been improved by the addition of omentopexy. ${ }^{11}$ The omental blood supply can maintain the viability of tracheal autografts less than $4 \mathrm{~cm}$ in length. ${ }^{5}$ In the diagnosis of rejection, epithelial morphology is valuable in identifying early rejection, because of its close association with epithelial regeneration. ${ }^{6,7}$ Thus the problem of immunosuppression must be studied in tracheal allotransplantation.

Allograft rejection can be both acute and chronic. Immunosuppression is commonly effective against acute rejection, but its role in chronic rejection still remains unclear because the mechanism of chronic rejection is not defined. Currently, consecutive immunosuppressive therapy for allografts, such as intensive immunosuppression in the acute phase which is tapered in the chronic phase, often is used clinically. ${ }^{12}$ The use of a short course of immunosuppression after transplantation is uncommon. Therefore, it is difficult to determine the most effective and shortest period of immunosuppression appropriate for tracheal allografts. Recognizing the tracheal allograft as the sensitizing antigen may take a relatively long time because the allografts are not vascularized initially, and revascularization occurs later. As a result, rejection of the allograft begins later, in contrast to other organ transplants. In our previous studies, the histopathologic status of allograft rejection was clearly apparent by 10 days after transplantation. ${ }^{7}$ Davreux and associates ${ }^{2}$ have reported that early rejection was apparent histologically by 14 days after transplantation. Therefore, tracheal allografts may require intensive immunosuppression for at least $\mathbf{1 4}$ days. In these current experiments, dogs with allografts in groups II, III, and IV, which received azathioprine for less than 14 days, showed no difference in such parameters as survival, graft patency, epithelial regeneration, and mononuclear cell infiltration. In contrast, three of five dogs with allografts in groups $\mathrm{V}$, which received azathioprine for 21 days, demonstrated improved 


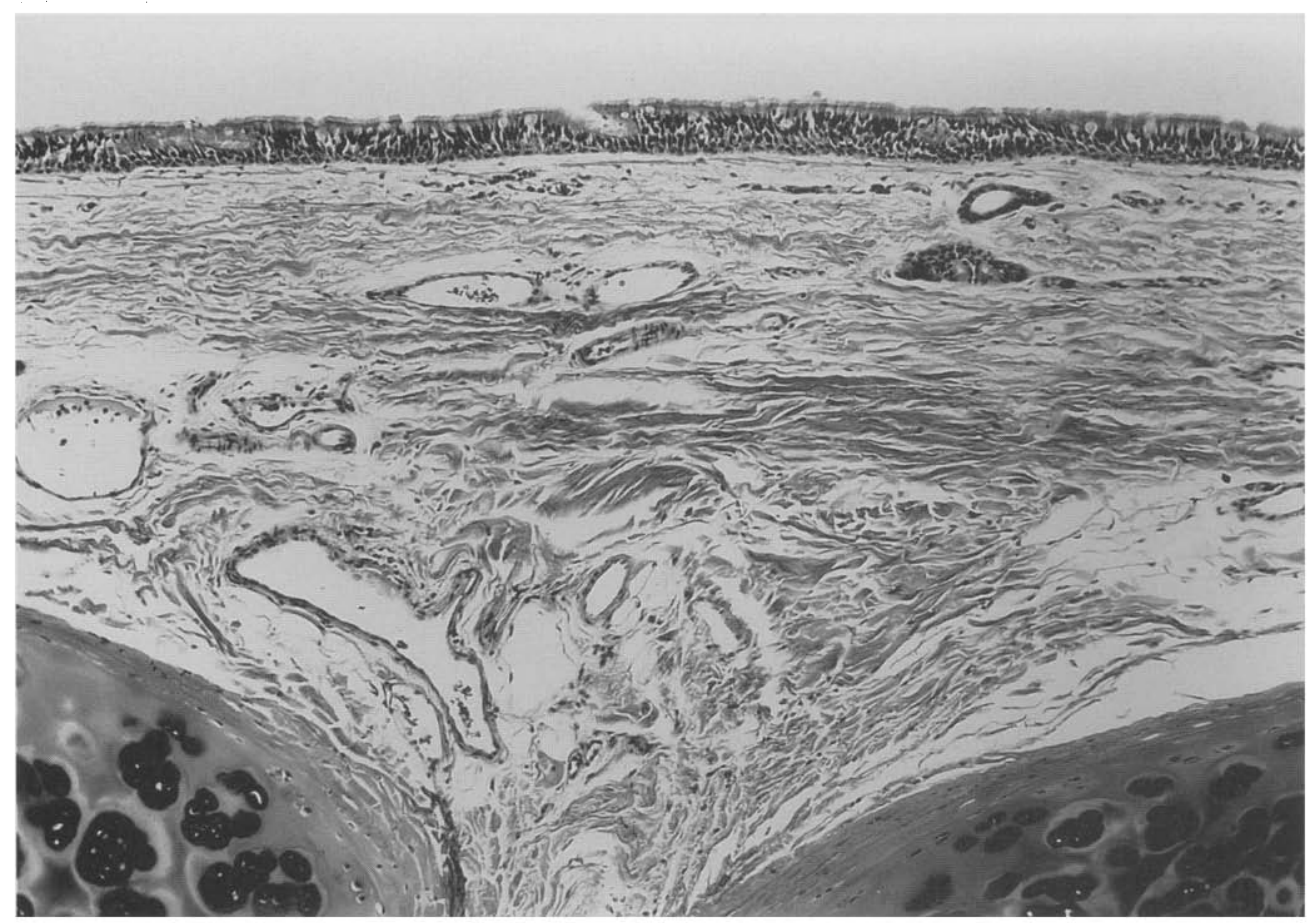

Fig. 4. Histologic study of an allograft of canine trachea on the postoperative day 811 in group VI (dog $30)$. The epithelium is almost restored and is composed of nearly normal mucociliary epithelium $(72.5 \%)$ (epithelial regeneration score $=2.45$ ). The mononuclear cells infiltrate only slightly into the subepithelial region of the graft. (Hematoxylin and eosin; original magnification $\times 250$.)

gross healing. The patency and epithelial regeneration of allografts in group $\mathrm{V}$ were slightly better than those of groups II, III, and IV. Therefore, it is thought that tracheal allografts may require immunosuppression for at least 21 days.

We used azathioprine and mizoribine as immunosuppressive agents in these experiments because these two agents can influence both cell-mediated and humoral immune reactions. ${ }^{13}$ These agents potentially induce the allografts to attain immune tolerance because they suppress both $\mathrm{T}$ and $\mathrm{B}$ lymphocytes. ${ }^{14}$ Azathioprine is a conventional immunosuppressant and has been used with corticosteroids in tracheal transplantation. ${ }^{10}$ In contrast, mizoribine, an imidazole nucleoside isolated from Eupenicillium brefeldianum M-2166, is a comparatively new drug and was originally developed as a $\mathrm{T}$ cell inhibitor. ${ }^{14}$ It was then found that mizoribine suppresses antibody generation by directly acting on $B$ cells as well as by indirect action through the modulation of $\mathrm{T}$ cells. ${ }^{15}$ Fundamentally, cytotoxic effect of mizoribine is caused by inhibition of synthesis of guanosine 5'-monophosphate in purine synthesis. ${ }^{16}$ In organ toxicity, mizoribine causes no

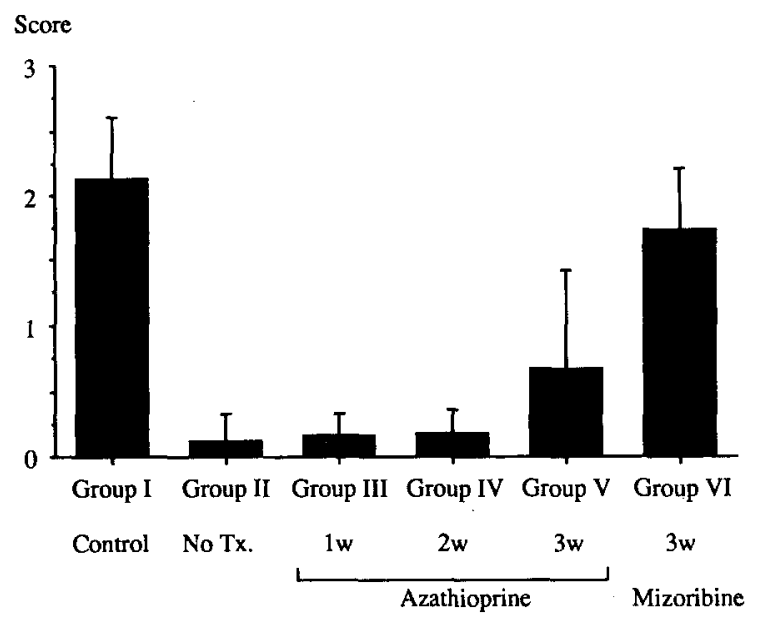

Fig. 5. Average epithelial regeneration score. Data are presented as mean \pm standard error. No $T x$. indicates no treatment. The average score of group I differed significantly from the score of the other four groups (groups I versus II, $p=0.0018$; I versus III, $p=0.0011$; I versus IV, $p=0.0007$; and I versus $\mathrm{V}, p=0.0021)$, but did not differ significantly from the score of group VI $(p=0.3696)$. The average score of group VI differed significantly from the score of groups II, III, and IV. 


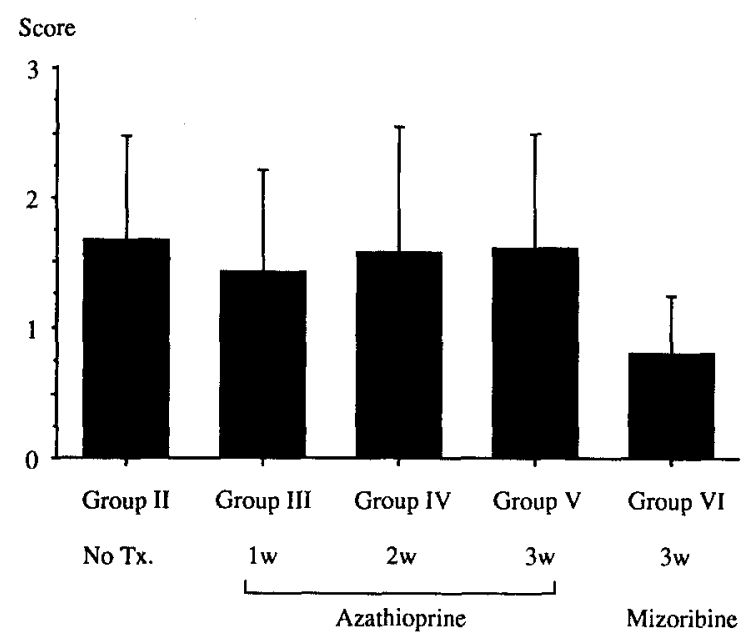

Fig. 6. Average mononuclear cell infiltration score. Data are presented as mean \pm standard error. No $T x$. indicates no treatment. In all comparisons of average score among groups II to VI, there was no difference.

manifest liver dysfunction or bone marrow suppression, as is often the case with azathioprine. ${ }^{14}$ In pharmacokinetics, mizoribine is not significantly metabolized and depends on renal excretion for termination of its action. ${ }^{13}$ Thus mizoribine has lesser side-effects but potency comparable with that of azathioprine. However, the dose of mizoribine equivalent to azathioprine still is not clear. We administered the two drugs at the same dosage of 5 $\mathrm{mg} / \mathrm{kg}$ per day. In experimental renal allotransplantation, azathioprine at a dosage of $5 \mathrm{mg} /$ day did not prolong allograft survival when compared with the same dose of mizoribine because of pneumonia caused by side-effects such as leukopenia. ${ }^{13}$ In our study, graft patency, epithelial regeneration, and mononuclear cell infiltration of the graft did not differ significantly between groups $V$ (azathioprine) and VI (mizoribine) at the same dosage, but survival, alone, significantly differed. In other words, the immunosuppressive effect of these two drugs is almost equivalent, but untoward side-effects of azathioprine may decrease survival. Therefore, the dose of azathioprine may be inadequate for full immunosuppression. Alternatively, mizoribine used for only 3 weeks after transplantation maintained the morphologic features of the tracheal allografts over a long period, as evidenced by graft patency and epithelial regeneration score. Mizoribine may better control allograft rejection in the acute phase after transplantation and then induce the allografts to almost attain immune tolerance. Alternatively, the tracheal allografts may induce only weak rejection in the late phase after transplantation. Mizoribine may be an adequate immunosuppressant for allograft rejection of the trachea in the acute phase after transplantation.

We conclude that an appropriate immunosuppressive agent used for only a short period after transplantation may nearly maintain the viability of the tracheal allograft over a long period. It is important to aggressively prevent and treat allograft rejection in the early phase after transplantation. Additional study is required to determine the most appropriate late-phase immunosuppressive therapy for tracheal allografts, such as whether low-dose consecutive or common-dose intermittent immunosuppression is more beneficial.

We thank Professor Masato Ikeda for performing the statistical evaluation and Ms. Miki Kiyofuji for her expert technical assistance.

\section{REFERENCES}

1. Veith FJ, Norin AJ, Montefusco CM, et al. Cyclosporin-A in experimental lung transplantation. Transplantation 1981;32:474-81.

2. Davreux CJ, Chu NH, Waddell TK, Mayer E, Patterson GA. Improved tracheal allograft viability in immunosuppressed rats. Ann Thorac Surg 1993;55:131-4.

3. Rose KG, Sesterhenn K, Wustrow F. Tracheal allotransplantation in man. Lancet 1979;24:433.

4. Nakanishi R, Shirakusa T. Tracheal reconstruction in 29 canines using allograft: a surgical technique [in Japanese]. J University of Occupational and Environmental Health 1991;13:47-51.

5. Nakanishi R, Shirakusa T, Mitsudomi T. Maximum length of tracheal autografts in dogs. J THORAC CARDIOVASC SURG 1993;106:1081-7.

6. Lane BP, Habicht GS, Jasper GS. Lymphocyte-epithelium interaction during rejection of nonisogeneic rat tracheal grafts. Am J Pathol 1977;86:71-7.

7. Nakanishi R, Shirakusa T, Hanagiri T. Early histopathologic features of tracheal allotransplantation rejection: a study in nonimmunosuppressed dogs. Transplant Proc 1994;26:3715-8.

8. Kaplan E, Meier P. Nonparametric estimation from incomplete observations. J Am Stat Assoc 1958;53: 457-81.

9. Peto $\mathrm{R}$, Pike MC, Armitage $\mathrm{P}$, et al. Design and analysis of randomized clinical trials requiring prolonged observation of each patient. $\mathrm{Br} \mathrm{J}$ Cancer 1976;34:585-612.

10. Neville WE, Bolanowski PJP, Soltanzadeh H. Homograft replacement of the trachea using immunosuppression. J Thorac Cardiovasc Surg 1976;72: 596-601. 
11. Nakanishi R, Shirakusa T, Takachi T. Omentopexy for tracheal autografts. Ann Thorac Surg 1994;57:841-5.

12. Hoyos AL, Patterson GA, Maurer JR, Ramirez JC, Miller JD, Winton TL, The Toronto Lung Transplant Group. Pulmonary transplantation: early and late results. J ThORAC CARDIOVASC SuRG 1992;103:295-306.

13. Okubo M, Kamata K, Yokota K, et al. Effect of Bredinin on cellular and humoral immune responses and on canine kidney allograft survival. Transplant Proc 1980;12:515-9.
14. Uchida H, Yokota $\mathrm{K}$, Akiyama $\mathrm{N}$, et al. Effectiveness of a new drug, bredinin, on canine kidney allotransplant survival. Transplant Proc 1979;11:865-70.

15. Okubo M, Chen XM, Kamata K, Masaki Y, Uchiyama T. Suppressive effect of mizoribine on humoral antibody production in DBA/2 mice. Transplantation 1986;41:495-8.

16. Sakaguchi $\mathrm{K}$, Tsujino $\mathrm{M}$, Yoshizawa $\mathrm{M}$, Mizuno $\mathrm{K}$, Hayano K. Action of Bredinin on mammalian cells. Cancer Res 1975;35:1643-7.

\section{Availability of Journal back issues}

As a service to our subscribers, copies of back issues of THE Journal of Thoracic ANd Cardiovascular SuRGER for the preceding 5 years are maintained and are available for purchase from the publisher, Mosby-Year Book, Inc., at a cost of $\$ 12.00$ per issue. The following quantity discounts are available: $25 \%$ off on quantities of 12 to 23 , and one third off on quantities of 24 or more. Please write to Mosby-Year Book, Inc., Subscription Services, 11830 Westline Industrial Drive, St. Louis MO 63146-3318, or call (800)453-4351 or (314)453-4351 for information on availability of particular issues. If unavailable from the publisher, photocopies of complete issues are available from University Microfilms International, 300 N. Zeeb Rd., Ann Arbor, MI 48106 , (313) $761-4700$. 